08,13

\title{
Структура и механизмы образования наноразмерных пленок примесного металла кобальта и никеля в монокристаллах $\mathrm{LiF}$ и $\mathrm{MgF}_{2}$
}

\author{
() Н.А. Иванов ${ }^{1}$, С.А. Небогин ${ }^{1}$, С.С. Колесников ${ }^{1}$, Л.И. Брюквина ${ }^{2}$ \\ ${ }^{1}$ Иркутский национальный исследовательский технический университет, \\ Иркутск, Россия \\ ${ }^{2}$ Иркутский филиал Института лазерной физики СО РАН, \\ Иркутск, Россия \\ E-mail: ivnik@istu.edu
}

Поступила в Редакцию 9 апреля 2021 г.

В окончательной редакции 9 апреля 2021 г.

Принята к публикации 19 апреля 2021 г.

Исследовано термическое травление кристаллов $\mathrm{LiF}_{\text {и }} \mathrm{MgF}_{2}$ с примесями кобальта и никеля методами растровой электронной микроскопии и атомно-силовой микроскопии с использованием декорирования. Показано, что примесные включения выходят из кристалла на его поверхность из дислокаций. Имеются различия между термическим травлением в вакууме и воздушной атмосфере. Кристаллографически ориентированные террасированные ямки травления образуются после выхода примесей из дислокаций. Прямоугольные ямки термического травления образуются после отжига кристалла при $750^{\circ} \mathrm{C}$ на воздухе. При термическом травлении образуется поверхностная металлсодержащая наноразмерная пленка. Окисление поверхностных примесей наблюдается при термическом травлении в атмосфере воздуха или в атмосфере остаточного воздуха.

Ключевые слова: $\mathrm{LiF}, \mathrm{MgF}_{2}$, термическое травление, примеси никеля и кобальта, дислокация.

DOI: $10.21883 /$ FTT.2021.09.51263.15H

\section{1. Введение}

Известно, что полезные применения ионных кристаллов во многом зависят от наличия в них дефектов, которые могут ухудшать гомогенность и однородность кристаллов. Эти дефекты могут появляться неконтролируемым образом в процессе роста кристалла и во многом определяются примесным составом шихты. Однако, часто в шихту для выращивания специально добавляются примеси для получения определенных свойств кристалла. В этом случае дефектов, ухудшающих качество исходных выращенных и радиационно-обработанных кристаллов, становится больше. В облученных щелочногалоидных кристаллах (ЩГК) могут присутствовать скопления примесей и вакансий, дислокации и поры, светорассеивающие наночастицы [1-4]. Для получения кристаллов $\mathrm{LiF}$ и $\mathrm{MgF}_{2}$ с определенными оптическими характеристиками производится легирование примесями двухвалентных металлов, таких как магний, кобальт, никель и другие $\left(\mathrm{Mg}^{2+}, \mathrm{Co}^{2+}, \mathrm{Ni}^{2+}\right.$ и др.) [5-9]. В отличие от примеси магния, примеси кобальта и никеля имеют плохую изоморфную совместимость с ионами лития $\mathrm{Li}^{+}$и фтора $\mathrm{F}^{-}$. Они могут встраиваться не только в узлы решетки, но и скапливаться в дислокациях, границах блоков и других протяженных дефектах. Актуальность проблемы изучения структуры и формы вхождения в кристалл примесных комплексов связана с тем, что кристаллы $\mathrm{LiF}$ используются в качестве лазерных сред, дозиметров ионизирующих излучений, для изучения фундаменталь- ных свойств центров окраски и молекулярных точечных дефектов [10-17].

F-агрегатные центры окраски, в частности, $\mathrm{F}_{2}^{+}$-центры, в кристаллах $\mathrm{LiF}$ с двухвалентными катионными примесями типа $\mathrm{Mg}^{2+}, \mathrm{Ni}^{2+}, \mathrm{Co}^{2+}$, созданные радиационной обработкой различными видами ионизирующих излучений, являются лазерно-активными центрами свечения, имеющими повышенную температурную стабильность за счет влияния катионных примесей $[18,19]$. Стабильность центров свечения обеспечивается наличием примесно-вакансионных диполей (ПВ-диполей). Катионная вакансия $\left(V_{c}^{-}\right)$компенсирует избыточный заряд металлической примеси. Однако, ПВ-диполи $\left(\mathrm{Me}^{2+} \mathrm{V}_{c}^{-}\right)$могут встраиваться в кристалл не в виде одиночных диполей, а в виде агрегатов диполей и других более сложных кластеров, что является нежелательным для стабилизации лазерно-активных центров окраски. Поэтому вопрос о форме вхождения двухвалентных катионных примесей во фторид лития является актуальным, тем более что примеси переходных металлов имеют более низкую изоморфную совместимость, чем примесь магния, наиболее часто вводимая в решетку $\mathrm{LiF}$ для получения соответствующих люминесцентных свойств центров окраски. Кристаллы фторида магния имеют возрастающую популярность в течение последних десятилетий, поскольку они являются идеальным просветляющим покрытием для лазерных устройств, важным материалом в волоконно-оптической связи из-за широкой запрещенной зоны, низкого показателя преломления, высокой меха- 
нической прочности. Перестраиваемые лазеры на основе $\mathrm{MgF}_{2}$, легированного кобальтом или никелем, являются сверхширокополосными лазерами среднего инфракрасного диапазона при комнатной температуре [20,21]. Интерес представляет также выяснение особенностей встраивания примесей переходных металлов в решетки $\mathrm{MgF}_{2}$ и $\mathrm{LiF}$, имеющих разные заряды кристаллообразующих катионов. Термический отжиг исходно выращенных или радиационно-обработанных кристаллов приводит к образованию металлических пленок на поверхности. Изучение в дальнейшем возможности применения этих пленок для создания нелинейных оптических приборов, для записи информации с использованием их в качестве оптических и магнитных носителей также требует внимания к исследованию примесей двухвалентных металлов как внутри кристалла, так и на его поверхности.

Термический высокотемпературный отжиг (или термическое травление) выращенных кристаллов приводит к тому, что часть примеси более равномерно распределяется по кристаллу, другая часть выходит на поверхность кристалла. Когда проводится термический отжиг и кристалл нагревается до высокой температуры, идет испарение с поверхности, т.е. процесс, обратный тому, что происходит при росте; при этом часто образуются ямки травления. Термические ямки травления могут коррелировать с дислокациями, выявленными химическим травлением [22,23]. Нами не проводилось химическое травление, но нас интересовал вопрос о том, из каких областей кристалла выходит примесь при термическом травлении: либо процесс связан с диффузией ПВ-диполей, либо с выходом примеси из дислокаций и других протяженных дефектов, содержащих примеси.

Механизм термического травления сравнивается с химическим травлением. Однако, имеется принципиальное различие между термическим и химическим травлениями. При термическом травлении перенос испаряемого материала идет только в направлении от поверхности. Следовательно, термическое травление может определяться объемной диффузией испаряемого материала, когда испарение осуществляется в некой газовой атмосфере. Считается, в вакууме объемная диффузия не может иметь места [24].

С помощью различных методов, таких как травление, декорирование, дифракция рентгеновских лучей, различного типа микроскопические методы, можно изучать термические преобразования примесей и дислокаций, как в объеме материала, так и на поверхности кристаллов. При выборе методов исследования мы руководствовались их эффективностью.

Мы поставили задачу изучить процесс термического травления на воздухе и в вакууме в кристаллах $\mathrm{LiF}: \mathrm{Co}$, $\mathrm{LiF}: \mathrm{Ni}, \mathrm{MgF}_{2}: \mathrm{Co}, \mathrm{MgF}_{2}: \mathrm{Ni}$ и распределение примеси и примесных комплексов, появившихся на поверхности кристаллов, методами электронной растровой и атомносиловой микроскопии с использованием декорирования.

\section{2. Экспериментальные методики}

Кристаллы LiF:Co, LiF:Ni были выращены методом Чохральского в атмосфере аргона с добавлением в шихту 0.2 wt.\% безводного $\mathrm{CoF}_{2}$ или $\mathrm{NiF}_{2}$ соответственно. Кристаллы $\mathrm{MgF}_{2}: \mathrm{Co}, \mathrm{MgF}_{2}: \mathrm{Ni}$ выращивались методом Чохральского в атмосфере аргона из расплава $\mathrm{MgF}_{2}$ с добавлением 1 wt\% $\mathrm{CoF}_{2}$ или $\mathrm{NiF}_{2}$. В соответствии с проведенными нами оптическими измерениями $[5,25]$, необлученные кристаллы $\mathrm{LiF}: \mathrm{Co}, \mathrm{LiF}: \mathrm{Ni}$, и $\mathrm{MgF}_{2}: \mathrm{Co}$, $\mathrm{MgF}_{2}$ : Ni имели характерные спектры поглощения, обусловленные оптическими переходами в двухвалентных примесных ионах в области спектра 200-1650 nm. Контроль ИК-поглощения показал отсутствие в спектре поглощения комплексов металл-гидроксил или свободного гидроксила.

Образцы для отжига размером приблизительно $5 \times 5 \times 1 \mathrm{~mm}$ были отколоты от кристаллов и термически травились в воздухе и в вакууме в муфельной печи при температурах $750-900^{\circ} \mathrm{C}$ в течение $2 \mathrm{~h}$ каждый. Визуально на поверхности кристаллов наблюдалось образование слабоокрашенной пленки, однако, измерение спектра поглощения в УФ- и видимом диапазонах с помощью спектрофотометра Karl Zeiss Specord UVVIS, показало лишь широкие полосы, принадлежащие рассеивающим металлосодержащим наночастицам разных размеров [26].

Для отжига в вакууме кристаллы помещались в кварцевую трубку, которая присоединялась к вакуумной системе и вводилась внутрь печи через специальное отверстие в передней дверце. Трубка откачивалась с помощью вакуумного насоса до остаточного давления $10^{-5}$ Torr. Печь нагревалась вместе с образцом до конечной температуры отжига $750^{\circ} \mathrm{C}$ приблизительно за $40 \mathrm{~min}$. Отжиг в воздушной атмосфере производился в керамическом тигле в закрытой печи. После отжига образцы остывали до комнатной температуры, находясь в закрытой печи. Поверхности образцов анализировались с помощью электронно-ионного растрового микроскопа JEOL JIB-4500 с напылением на поверхность тонкой пленки золота. Элементный анализ проводился с помощью энергодисперсионного детектора фирмы Oxford. Элементный анализ проводился как в отдельных точках, так и путем картирования элементов поверхности. Рельеф и структура поверхности кристаллов изучались с помощью сканирующего зондового микроскопа Solver P47-PRO.

\section{3. Термическое травление в вакууме}

\section{1. Кристалл LiF : Ni}

Кристалл $\mathrm{LiF}: \mathrm{Ni}$ был отожжен при температуре $750^{\circ} \mathrm{C}$ в вакууме $10^{-5}$ Torr в течение $2 \mathrm{~h}$. В неотожженном кристалле на поверхности скола (100) никаких примесей и неоднородностей не наблюдалось (рис. 1, $a$ ). 
$a$

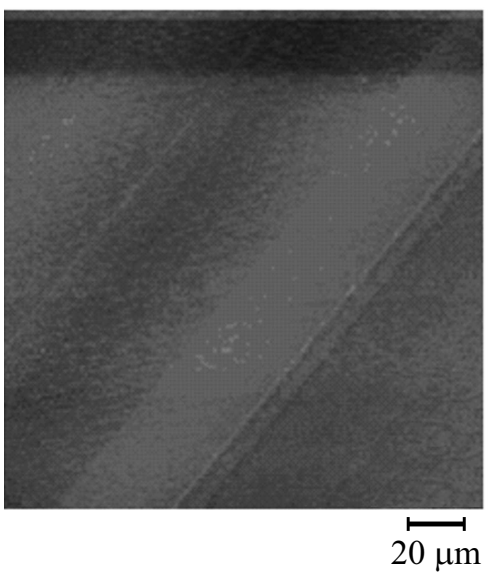

$b$

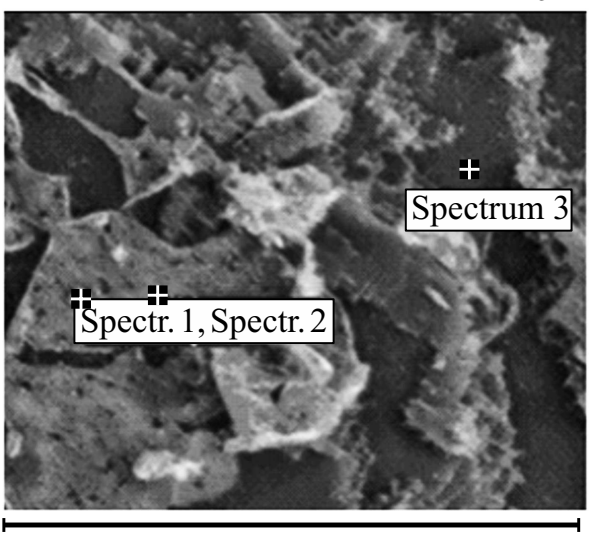

$60 \mu \mathrm{m}$

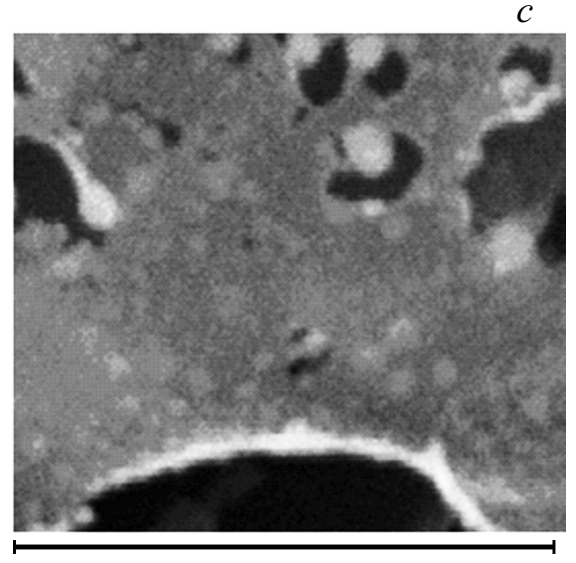

$3 \mu \mathrm{m}$

Рис. 1. Изображение поверхности кристалла $\mathrm{LiF}: \mathrm{Ni}$ после термического травления при $750^{\circ} \mathrm{C}$ в течение $2-\mathrm{x}$ часов в вакууме: исходный неотожженный кристалл $(a)$, пленка, образованная термическим травлением, с указанием точек, в которых анализировалось содержание примесей $(b)$, дырки и неоднородности в пленке $(c)$.
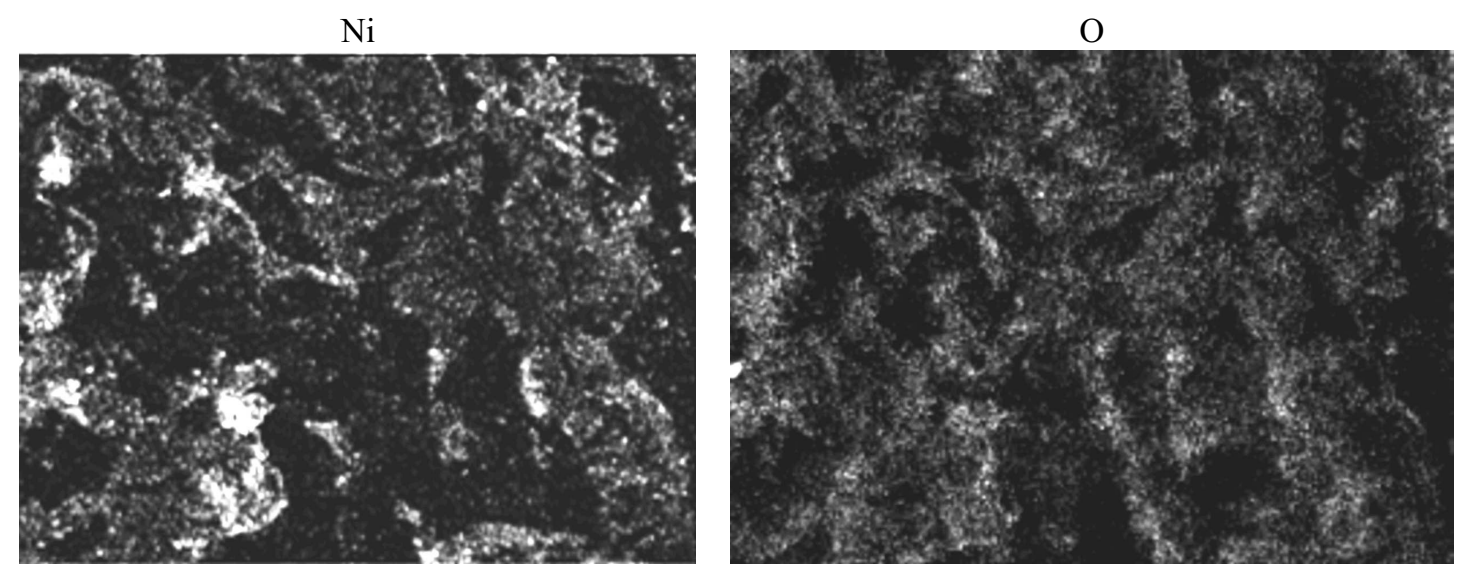

Рис. 2. Картирование элементов никеля и кислорода в поверхностной пленке кристалла LiF: Ni после термического травления в вакууме.

В результате отжига на поверхности образовалась неоднородная пленка (рис. $1, b)$, состоящая из областей с повышенным содержанием примесей никеля и кислорода (таблица). Для элементного анализа были выбраны точки 1 и 2 , находящиеся на поверхности пленки и точка 3 в области, свободной от пленки. Из таблицы видно, что в точках 1 и 2 пленки содержание никеля и кислорода примерно в 5 раз больше, чем в точке 3 , в которой

Содержание примесей никеля, кислорода и фтора в пленке (точки 1 и 2) и в промежутке пленки (точка 3) кристалла $\mathrm{LiF}: \mathrm{Ni}$ после термического травления в вакууме

\begin{tabular}{c|c|c|c|c}
\hline № спектра & O, wt\% & F, wt\% & Ni, wt\% & Итог (wt\%) \\
\hline 1 & 3.4 & 92.8 & 3.6 & 100.0 \\
\hline 2 & 2.3 & 94.5 & 3.0 & 100.0 \\
\hline 3 & 0.6 & 98.6 & 0.6 & 100.0
\end{tabular}

отсутствует пленка. Этот анализ позволяет считать, что в образованной пленке преобладают соединения никеля, связанные с кислородом. Кислородсодержащие примесные преципитаты появились на поверхности вследствие того, что кислород присутствовал в атмосфере отжига из-за недостаточного вакуума, или из-за десорбции из материала кварцевой трубки.

При уменьшении масштаба изображения в 20 раз можно увидеть, что никельсодержащая пленка имеет „дырки“ и неоднородности (рис. 1,c). Подобная картина наблюдалась в работе [26]. Картирование элементов показало наличие никеля и кислорода в пленке (рис. 2).

Картирование элементов показало также наличие в пленке фтора и углерода. Высокую концентрацию фтора в исследуемых точках (таблица) можно объяснить двумя причинами. С одной стороны, сквозь тонкую прозрачную никельсодержащую пленку в анализе мог регистрироваться фтор кристаллической матрицы LiF. C другой стороны, при термическом травлении происходит де- 


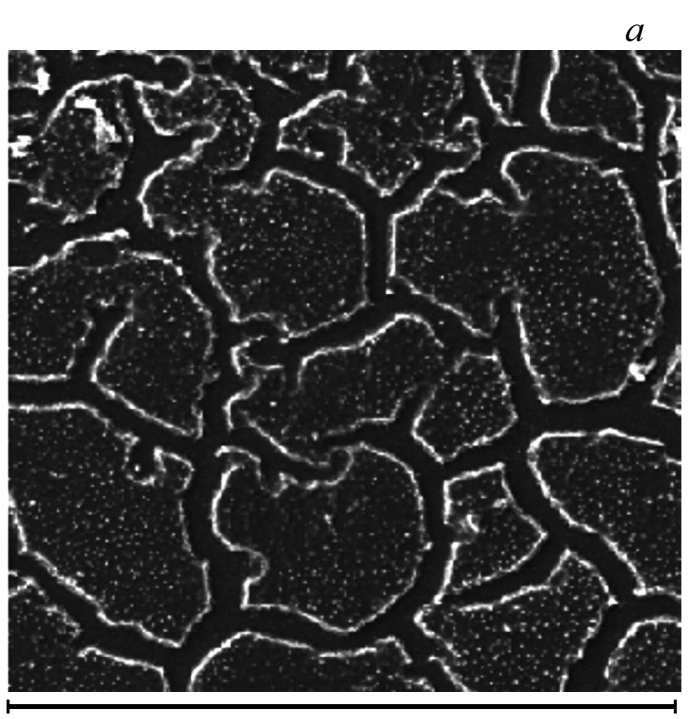

$400 \mu \mathrm{m}$

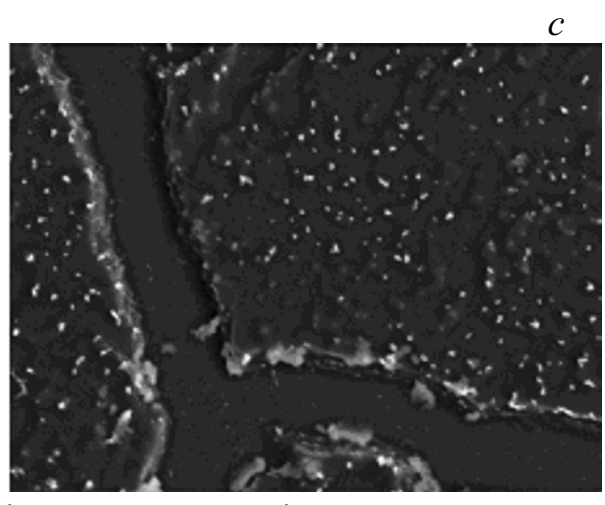

$60 \mu \mathrm{m}$

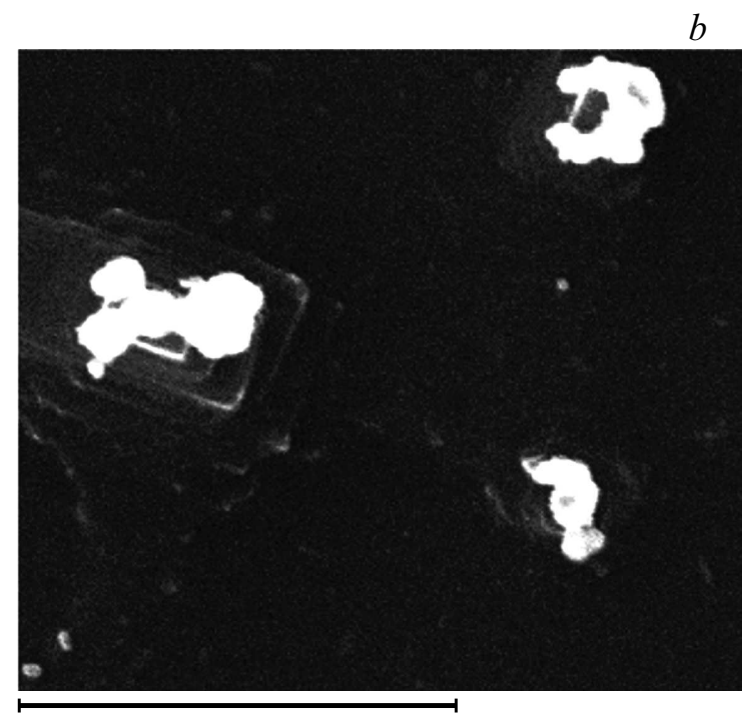

$5 \mu \mathrm{m}$

$d$

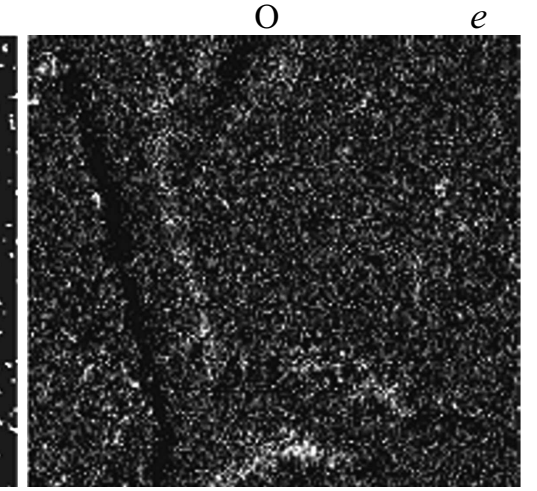

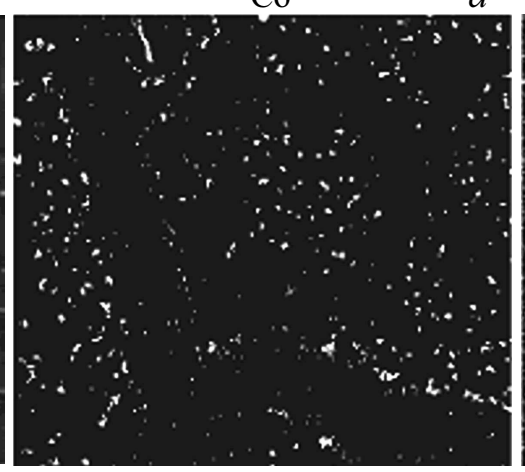

Pис. 3. Поверхность кристалла $\mathrm{LiF}$ : Со после термического травления при $750^{\circ} \mathrm{C}$ в течение 2 -х часов в вакууме: изображение разориентированных кристаллических зерен $(a)$, выход кобальтсодержащих преципитатов из ямок термического травления $(b, c)$, картирование элементов кобальта $(d)$ и кислорода $(e)$.

сорбция фтора с поверхности кристалла, который при высокой температуре может взаимодействовать с никелем и остаточными количествами атмосферных углекислого газа и кислорода и оседать в виде соответствующих соединений на поверхность скола кристалла.

\section{2. Кристалл LiF : Co}

На рис. 3, $а$ представлена поверхность скола кристалла $\mathrm{LiF}$ : Co, отожженного при $750^{\circ} \mathrm{C}$ в вакууме $10^{-5}$ Torr в течение $2 \mathrm{~h}$.

Поверхность скола состоит из разориентированных кристаллических зерен, или полигонов [27-29]. Зерна имеют различные размеры и форму (рис. 3,a). Между зернами пролегают широкие $(\sim 15 \mu \mathrm{m})$ границы, так называемые полигонизационные стенки. Преципитаты кобальтовых соединений отлагаются на поверхности зерен и границ. На рис. 3, $c$ представлена та же поверхность скола отожженного кристалла LiF : Co, но в более мелком масштабе (в $\sim 7$ раз меньше, чем на рис. $3, a)$.
На рис. 3, с отчетливо видны скопления кобальтсодержащей примеси. Примесь представлена белыми пятнами на темном фоне зерна и границы зерна. На рис. 3, b, масштаб которого в 12 раз меньше масштаба рис. 3, $c$, представлен выход кобальтсодержащих преципитатов из ямок термического травления на поверхность этого же образца. Картирование элементов кобальта и кислорода показало их наличие на поверхности отожженного скола. Видно, что примесь кобальта распределяется в отдельных точках поверхности, в то время как кислород распределен более равномерно по поверхности скола (рис. $3, d, e)$. В некоторых местах границы зерна содержат примеси натрия и хлора. Это объяснимо, поскольку на границах зерен скапливаются дислокации с примесями, закрепленными на них. Натрий, как катион, имеющий больший радиус, чем литий, вытесняется вместе с большим по размеру, чем фтор, хлором, на границу зерна, возможно, в виде соединения $\mathrm{NaCl}$. Снимки, представленные на рис. $3, d$ и $e$, указывают на то, что примесные преципитаты содержат кобальт и кислород. 


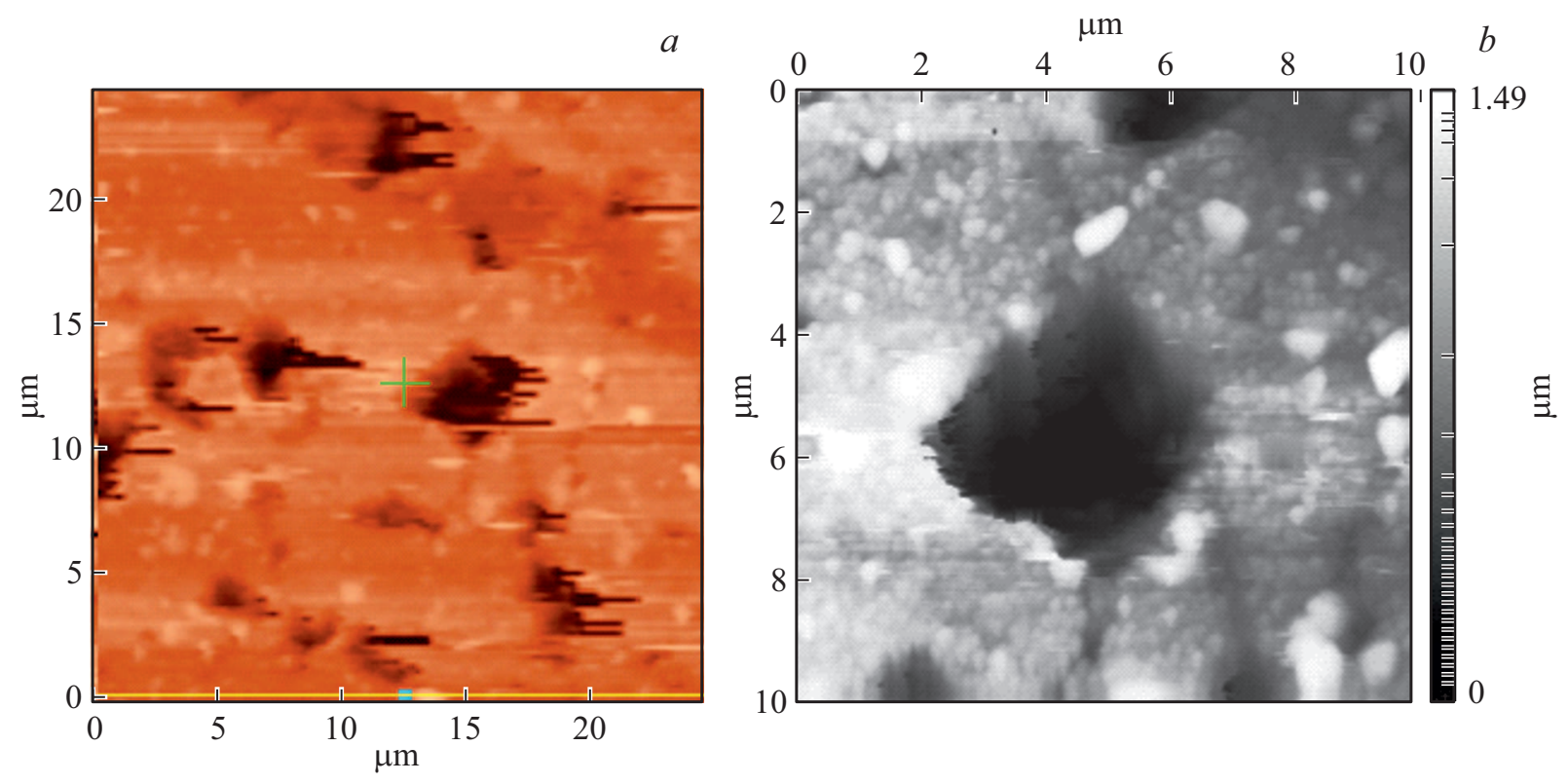

Рис. 4. Рельеф поверхности кристалла $\mathrm{LiF}: \mathrm{Co}$, радиационно обработанного и затем термически отожженного при $750^{\circ} \mathrm{C}$ в течение 2-х часов: снимок части поверхности $(a)$, ямка, помеченная крестиком на рис. $4 a$, в другом масштабе $(b)$.

Выход кобальтсодержащих преципитатов из ямок термического травления, которые кристаллографически ориентированы, представлен на рис. $3, b$. Однако среди них видны и ямки, которые имеют не четко выраженную прямоугольную форму. В работах $[22,23]$ считают, что каждая ямка термического травления, и каждый выход примеси из нее связан с отдельной дислокацией. Если это учесть, то плотность дислокаций можно оценить. По нашим подсчетам она равна $3.3 \cdot 10^{4} / \mathrm{cm}^{2}$.

Изображения, полученные с помощью сканирующего зондового микроскопа Solver P47-PRO, подтверждают образование термических ямок травления размерами приблизительно от 1 до $4 \mu \mathrm{m}$, которые преимущественно кристаллографически ориентированы и имеют прямоугольную форму (рис. 4, $a, b)$.

Формирование видимых резких контрастных ямок травления в местах выхода дислокаций является характерной особенностью химического травления. Необходимым условием формирования таких ямок является определенное соотношение между тремя скоростями растворения. Первая, нормальная скорость травления $V_{n}$ направлена вдоль дислокационной линии, по нормали к поверхности. Тангенциальная, или боковая, скорость травления $V_{t}$ описывает скорость распространения элементарных ступеней вдоль поверхности. Наконец, скорость $V_{p}$ отображает растворение поверхности в областях, свободных от дислокаций. Эта скорость также направлена по нормали к поверхности. Примесные кластеры в кристалле могут действовать подобно вакансионным кластерам, либо декорировать дислокации. Сегрегация примеси оказывает влияние на скорость роста ямок травления вдоль линии дислокации. Скорость роста ямок травления будет высока до тех пор, пока не встре-

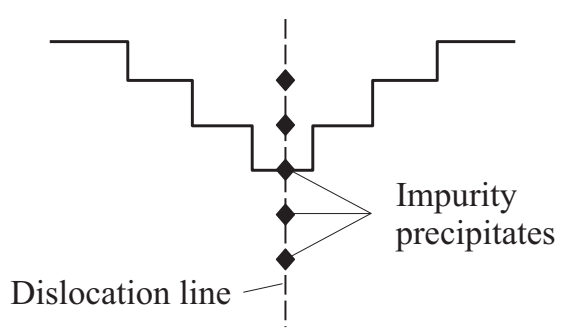

Рис. 5. Образование террасчатых ямок травления за счет преципитатов внутрикристаллической примеси, сконцентрировавшейся вдоль линии дислокации.

тятся преципитаты примеси (рис. 5), а в их окрестности скорость будет падать. Когда скорость зарождения низка, ступень, образовавшаяся в период высокой скорости зарождения, будет двигаться в сторону от линии дислокации. Если преципитат удаляется из ямки травления, то скорость роста ямки травления будет увеличиваться. Повторение такого процесса приведет к формированию ямки с рядом террас (рис. 5). Экспериментальные доказательства действия такого механизма получены для случая поверхности (100) кристаллов LiF [24]. В нашем случае проводилось термическое травление, но картина травления оказалась такой же. Поведение примесных преципитатов, наблюдаемое нами в результате термического травления, является аналогичным поведению, описанному в работе [24] (рис. 5).

Таким образом, на рис. 3 представлены террасчатые ямки термического травления, имеющие в идеальном случае квадратную форму. Можно сделать заключение, что они образуются таким же образом, как при химиче- 


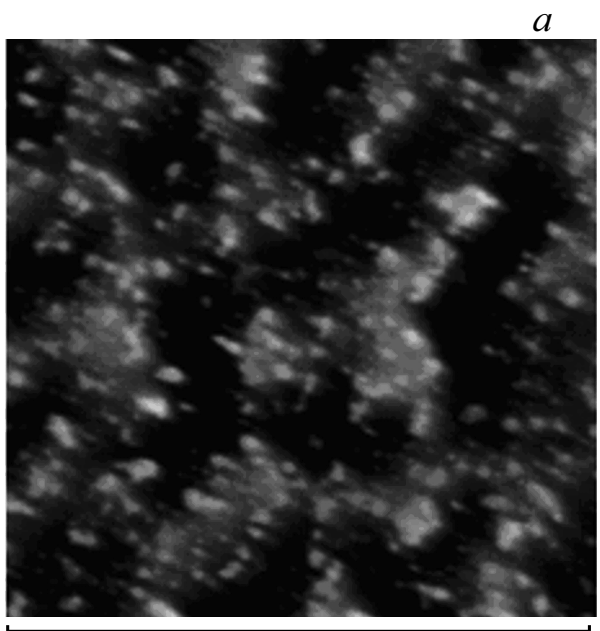

$10 \mu \mathrm{m}$

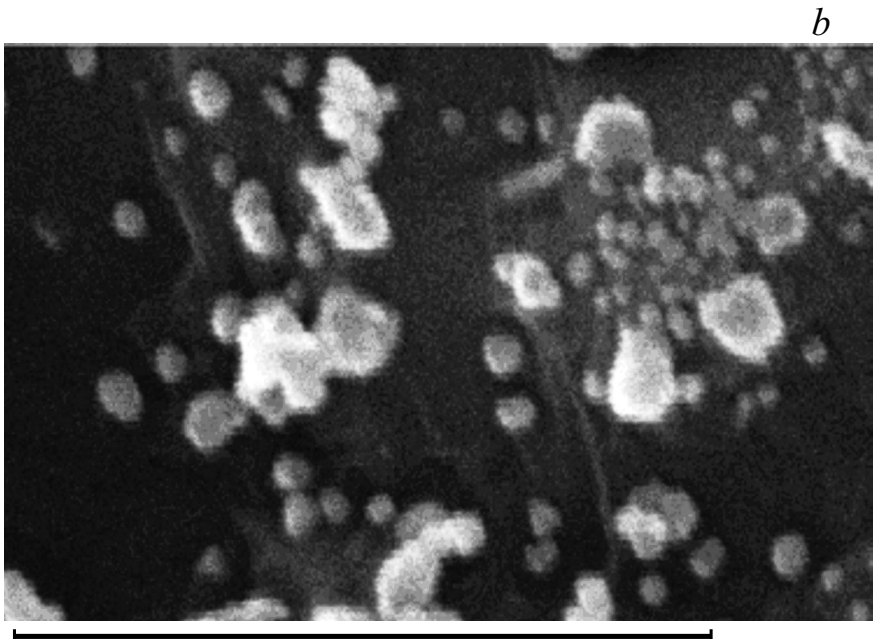

$3 \mu \mathrm{m}$

Рис. 6. Поверхность кристалла $\mathrm{MgF}_{2}$ : Со, отожженного при температуре $900^{\circ} \mathrm{C}$ в вакууме в течение $2-\mathrm{x}$ часов, с примесными преципитатами.

ском травлении. Показано, как примесные преципитаты кобальта выходят, формируя террасчатые ямки термического травления. Состав преципитатов определить сложно. Картирование элементов выявило равномерное покрытие поверхности скола не только кислородом, но и фтором. Наряду с фтором кристаллической матрицы на всей поверхности образца в примесных кобальтсодержащих включениях могут регистрироваться комплексные соединения фтора. Можно предположить, что в расплаве происходит реакция с образованием фторкомплексов, например: $\mathrm{CoF}_{2}+\mathrm{LiF} \rightarrow \mathrm{Li}\left[\mathrm{CoF}_{3}\right], \mathrm{Li}_{2}\left[\mathrm{CoF}_{4}\right], \mathrm{Li}_{4}\left[\mathrm{CoF}_{6}\right]$. Эти комплексы могут выходить из дислокаций, где они скапливаются во время роста, во включения на поверхности.

\section{3. Кристалл $\mathrm{MgF}_{2}$ : Co}

На рис. 6 представлен поверхностный скол кристалла $\mathrm{MgF}_{2}$ : Со, отожженного при $900^{\circ} \mathrm{C}$ в вакууме $10^{-5}$ Torr в течение $2 \mathrm{~h}$. На рис. $6, a$ представлена неоднородная пленка на поверхности, на которой наблюдаются высыпания примеси. Рис. $6, b$ более детально демонстрирует примесные включения разных размеров (от $\sim 900 \mathrm{~nm}$ до $500 \mu \mathrm{m})$ в пленке при большем увеличении, чем на рис. $6, a$. Элементный анализ показал, что во включениях повышенная концентрация кобальта и кислорода.

Неоднородность пленки объясняется неоднородным захватом примесей при росте кристалла. Примеси оседают на дислокациях или их скоплениях. В процессе отжига происходит миграция и укрупнение дислокаций и примесей, оседающих на них. Впоследствии преципитаты примесей выходят из скоплений дислокаций, формируя ямки термического травления.

\section{4. Кристалл $\mathrm{MgF}_{2}: \mathrm{Ni}$}

Кристалл $\mathrm{MgF}_{2}: \mathrm{Ni}$ отжигался при $900^{\circ} \mathrm{C}$ в вакууме $10^{-5}$ Torr в течение $2 \mathrm{~h}$. Поверхность кристалла $\mathrm{MgF}_{2}: \mathrm{Ni}$ после термического травления представлена на рис. 7.

Некоторая энергия напряжения кристаллической решетки всегда локализуется вокруг дислокаций, и из-за этой энергии локальная химическая активность при дислокациях увеличивается. Иными словами, при дислокациях растворение поверхности кристалла более эффективно, чем в относительно совершенных областях.

Морфология изменений, наблюдаемых на поверхности, может быть обусловлена сегрегацией примеси в дислокационных узлах [30]. Вследствие нагревания кристалла $\mathrm{MgF}_{2}: \mathrm{Ni}$ в условиях низкого вакуума и нахождения кристалла в кварцевой трубке образовалась окисленная поверхность, а ямы термического травления появились в местах скопления дислокаций и канавок (рис. 7). Резкое различие в морфологии поверхности связано с разной реакционной способностью поверхности кристалла. На рис. 7, $a$ представлена панорама термически протравленной поверхности отожженного кристалла $\mathrm{MgF}_{2}: \mathrm{Ni}$.

Видны почти периодически расположенные ямки травления и борозды травления. В бороздах травления наблюдаются примесные включения (рис. 7, $b$ ). Элементный анализ, проведенный в ямках, показал следующие весовые процентные концентрации примесей кислорода и никеля: $\mathrm{O}-0.73 \mathrm{wt} \%, \mathrm{Ni}-1.00 \mathrm{wt} \%$. Величины этих концентраций находятся на уровне концентраций примесей, содержащихся в выращенном и термически не обработанном кристалле. Поэтому можно сделать вывод, что примесные преципитаты никеля, выходя из ямок и бороздок, равномерно покрывают поверхность (рис. 7, $a, b$ ). 


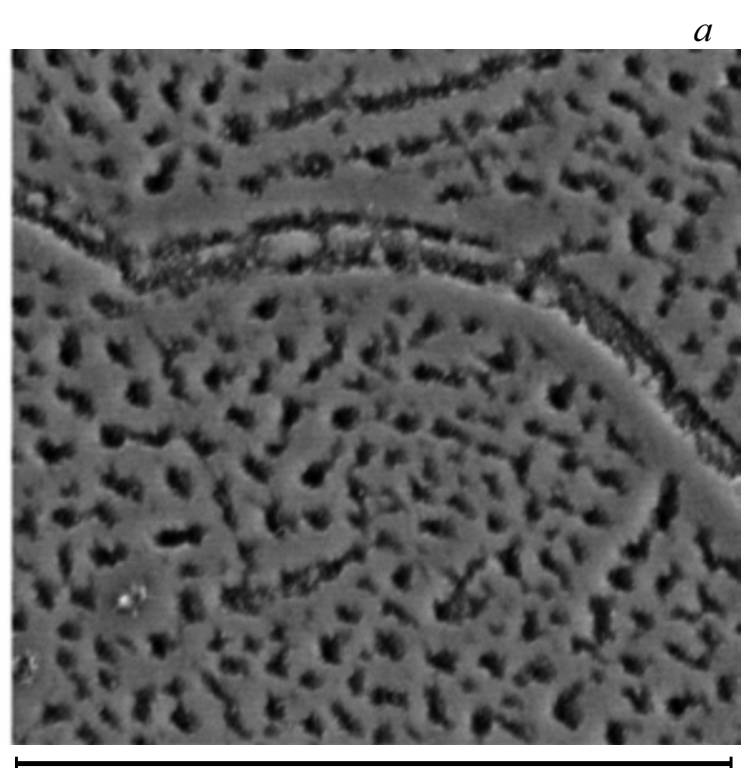

$40 \mu \mathrm{m}$

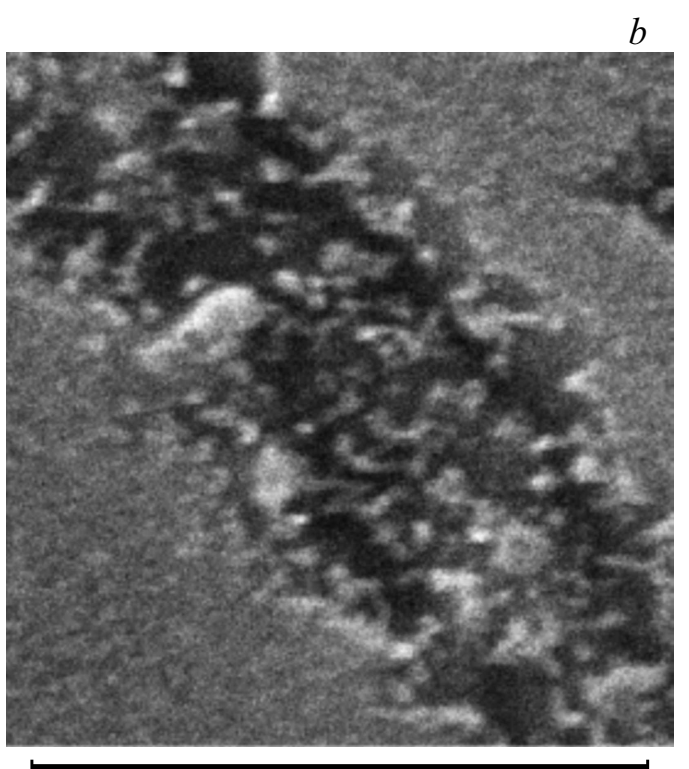

$4 \mu \mathrm{m}$

Рис. 7. Изображение поверхности кристалла $\mathrm{MgF}_{2}: \mathrm{Ni}$ после термического травления при $900^{\circ} \mathrm{C}$ в вакууме в течение $2-\mathrm{x}$ часов.

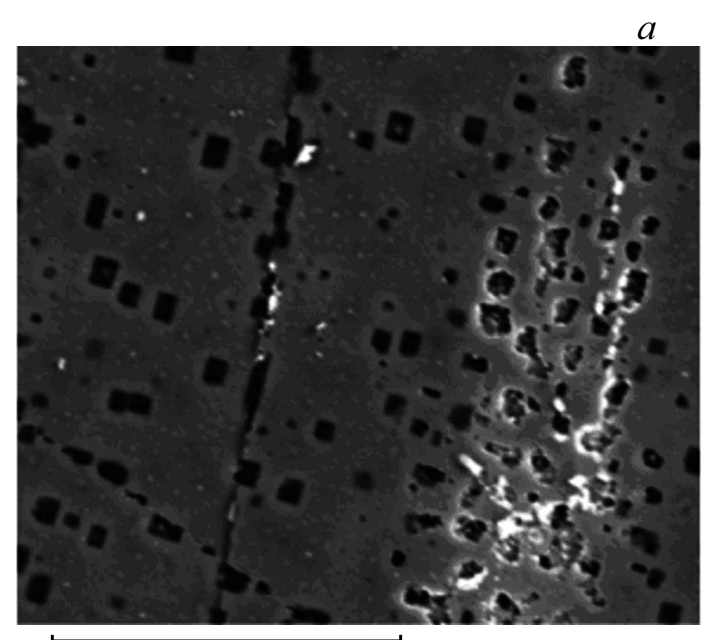

$60 \mu \mathrm{m}$

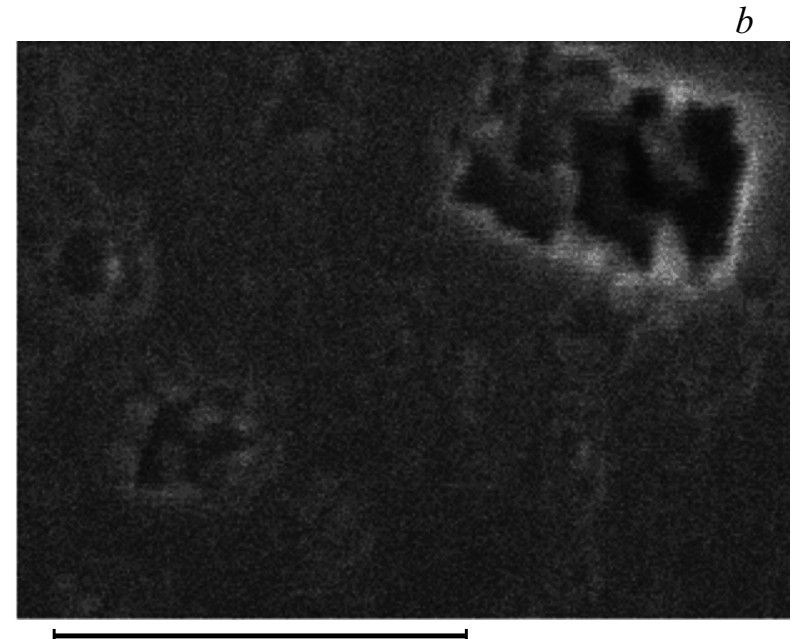

$1 \mu \mathrm{m}$

$\mathrm{O}$

$d$

$\mathrm{Ni}$
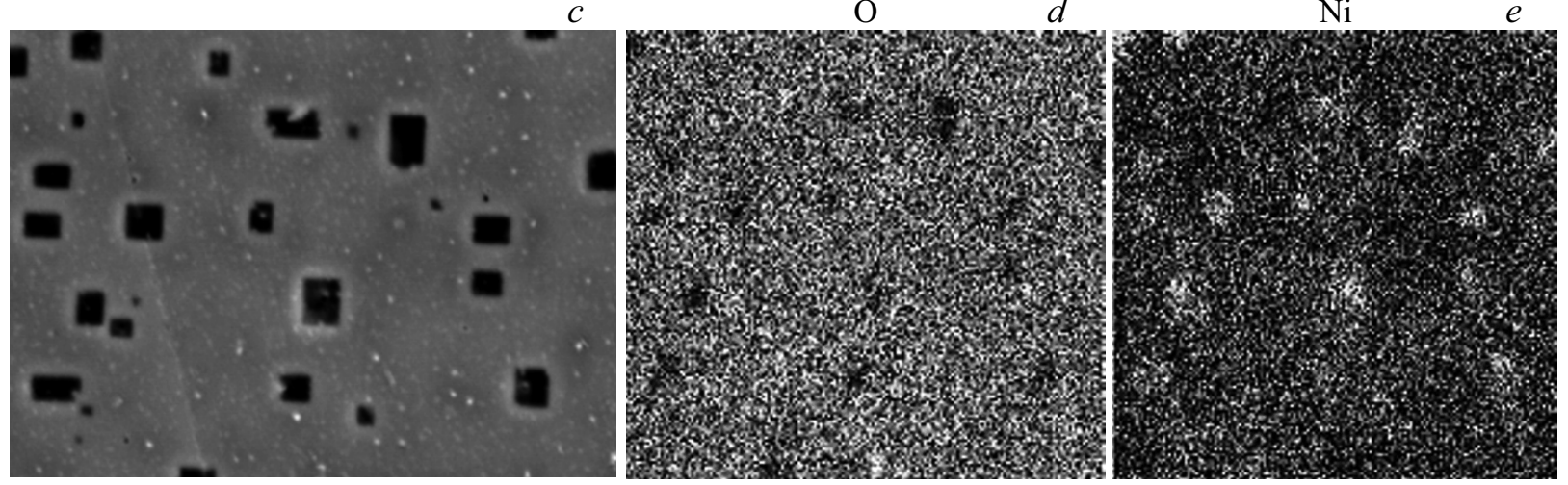

Рис. 8. Изображение поверхностной пленки кристалла $\mathrm{LiF}: \mathrm{Ni}$ после термического травления при $750^{\circ} \mathrm{C}$ в воздухе: общий вид пленки $(a, b)$, прямоугольные ямки термического травления $(c)$, картирование элементов кислорода и никеля в прямоугольных ямках $(d, c)$. 


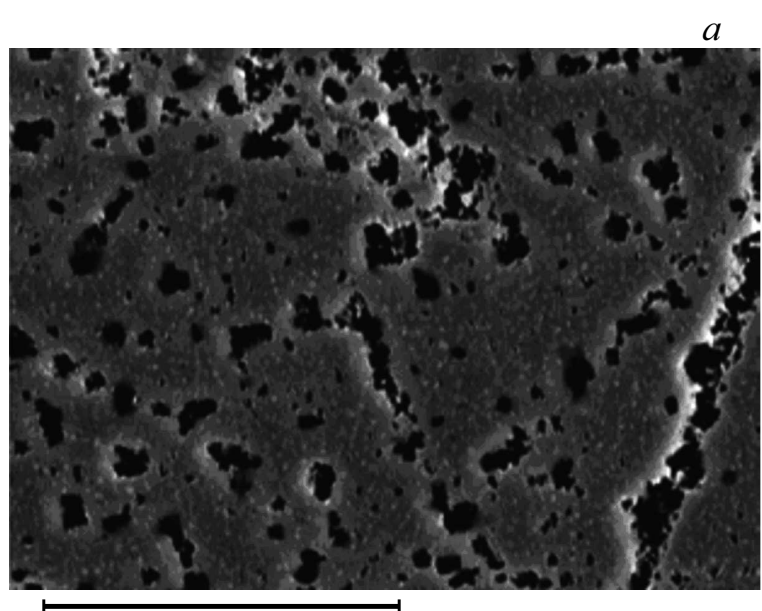

$40 \mu \mathrm{m}$

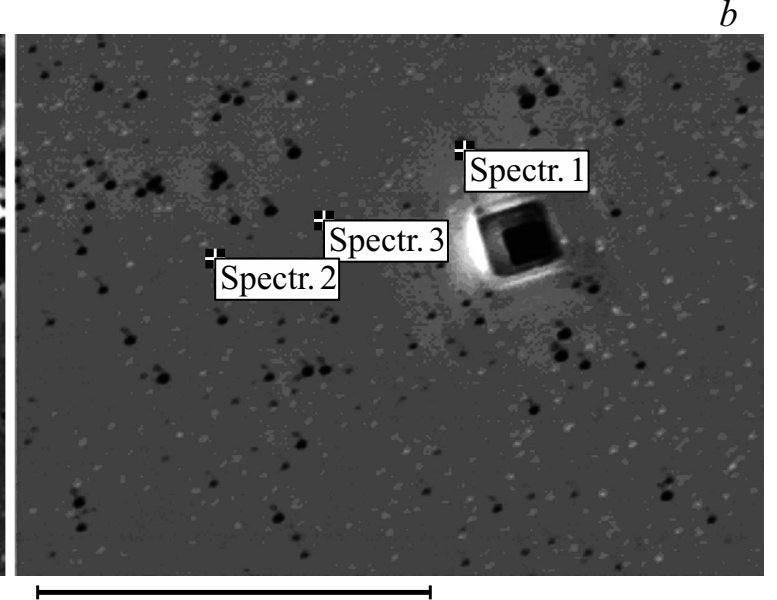

$20 \mu \mathrm{m}$

Рис. 9. Общая картина поверхности кристалла $\mathrm{LiF}$ : Со после термического травления при $750^{\circ} \mathrm{C}$ в течение 2 -х часов в воздухе $(a)$, квадратная ямка травления с террасами и точки, расположенные в ямках, в которых проводился элементный анализ $(b)$.

Таким образом, на поверхности отожженного при $900^{\circ} \mathrm{C}$ в вакууме кристалла $\mathrm{MgF}_{2}: \mathrm{Ni}$ образовалась никельсодержащая пленка с ,дырками“ и бороздками, в которых содержатся примесные включения.

\section{4. Термическое травление на воздухе}

\section{1. Кристалл LiF : Ni}

Кристалл $\mathrm{LiF}: \mathrm{Ni}$ был отожжен при температуре $750^{\circ} \mathrm{C}$ в воздухе в течение $2 \mathrm{~h}$.

Термическое травление на воздухе происходит в атмосфере, в которой присутствуют химически активные молекулы кислорода, которые окисляют находящийся на поверхности кристалла металл. Металлические атомы никеля, вышедшие под действием отжига на поверхность скола кристалла не только из ближайших к поверхности слоев, но и из объемных слоев кристалла (при термическом травлении в любой атмосфере примесь выходит не только из поверхностного слоя, но и из всего объема кристалла), создают пленку оксида никеля (рис. 8). В пленке присутствуют прямоугольные ямки травления в месте выхода дислокаций.

Как показал элементный анализ, в прямоугольных ямках термического травления наблюдается повышенное содержание никеля (до 16.78 wt\%) и фтора (максимально до $90.63 \mathrm{wt} \%$ ) и пониженное содержание кислорода (минимально до $1.17 \mathrm{wt} \%$ ). Значит, в прямоугольных ямках или местах выхода дислокаций содержится не окисленная примесь никеля. Поверхность пленки, исключая прямоугольные ямки, имеет повышенное содержание кислорода. О подобной картине термического травления сообщается в [24]. Не все ямки имеют прямоугольную форму (рис. $8, b$ ). Картирование элементов показывает, что в ямках наблюдается повышенное содержание никеля, а в пленке за пределами прямоуголь- ных ям травления равномерно распределен кислород (рис. $8, d, e)$. Значит, вследствие термического травления на воздухе поверхность кристалла $\mathrm{LiF}: \mathrm{Ni}$ покрылась пленкой оксидных соединений никеля. Также, в пленке присутствуют соединения углерода, что объясняется тем, что кристалл выращивали в графитовом тигле, и в атмосфере отжига всегда присутствует углекислый газ и другие углеродные соединения. В прямоугольных ямках наблюдается повышенное содержание никеля, что подтверждает идеи о том, что примеси скапливаются на дислокациях, поскольку прямоугольные ямки формируются в области дислокаций $[22,23,30]$. Повышенное содержание никеля и фтора в прямоугольных ямках травления можно объяснить тем, что никель и фтор могут образовать в процессе отжига, например фторид никеля $\mathrm{NiF}_{2}$. В процессе отжига при температуре $750^{\circ} \mathrm{C}$ могла происходить реакция: $\mathrm{Ni}+\mathrm{F}_{2} \rightarrow \mathrm{NiF}_{2}$.

\section{2. Кристалл LiF : Co}

Термическое травление на воздухе кристалла $\mathrm{LiF}$ : Co проводилось при температуре $750^{\circ} \mathrm{C}$ в течение $2 \mathrm{~h}$. В результате термического травления на поверхности кристалла появилась пленка, подобная той, которая образовалась вследствие термического травления кристалла LiF: Ni. Oсобенность этой пленки состоит в том, что „дырки“ в ней имеют не только прямоугольную форму, но и произвольную форму (рис. 9, $a$ ).

По результатам проведенного картирования элементов эта пленка также состоит из оксидных соединений кобальта, а в ,дырках“ и канавках наблюдается повышенное содержание кобальта, но пониженное содержание кислорода. Это говорит о том, что в процессе образования пленки участвует атмосферный кислород, a в „дырках“ и канавках скапливаются примесные преципитаты никеля без участия кислорода. На рис. 9, $b$ представлена квадратная ямка термического травления 
с террасами. Размер ямки травления равен приблизительно $2.5 \times 2.5 \mu \mathrm{m}$. Примесные кобальтовые преципитаты либо испарились из ямки в воздух, либо приняли участие в формировании оксидной пленки кобальта на поверхности образца. Контуры террас имеют идеальную квадратную форму со сторонами, параллельными скорее направлению [110], чем [100]. Несмотря на то что отжиг проводился достаточно продолжительное время, форма ямки осталась квадратной, хотя по некоторым данным с увеличением времени травления происходит превращение квадратных ям травления в круглые ямы [31].

\section{5. Заключение}

Для изучения процессов преобразования примеси в ионных кристаллах $\mathrm{LiF}$ и $\mathrm{MgF}_{2}$, намеренно легированных примесями кобальта и никеля, нами было проведено термическое травление при температурах 750 и $900^{\circ} \mathrm{C}$, соответственно, в течение $2 \mathrm{~h}$ в вакууме и в воздушной атмосфере.

Гринберг [32] и Будке [33] в своих исследованиях не нашли корреляции между дислокациями и термическими ямками травления. Также эти авторы не нашли определенной связи термической ямки с примесями. Проведенные нами эксперименты показали, что в результате термического травления в вакууме преципитаты примеси в ионных кристаллах $\mathrm{LiF}: \mathrm{Ni}, \mathrm{LiF}: \mathrm{Co}$ и $\mathrm{MgF}_{2}: \mathrm{Ni}$, $\mathrm{MgF}_{2}$ : Со выходят из дислокаций и скоплений дислокаций, образуя прямоугольные и квадратные террасчатые ямки травления. Террасчатые ямки ранее наблюдались авторами [34] с помощью оптического микроскопа на поверхности фтористого лития.

В работе [22] указывалось, что адсорбция примесей является необходимым условием для формирования термических ям. Нами показано, что при отжиге кристаллов в вакууме, в котором отсутствовала адсорбция примесей, термические ямы формировались в местах скопления внутренних примесей при дислокациях.

Таким образом, примесь играет решающую роль при формировании термических ям в обоих случаях: в случае адсорбции извне и в случае присутствия ее внутри кристалла.

Образование дислокационных ямок травления во фториде лития при термическом травлении происходит так же, как образование ямок травления разбавленным водным раствором фторида железа [34]. Этот процесс можно представлять как процесс преимущественного зарождения единичных ям при дислокациях, и торможение движения краев этих ям ионами переходных металлов, таких как кобальт и никель. Эффект ионов кобальта и никеля заключается в замедлении движения ступеней через кристалл, производящий ямки травления. Ионы двухвалентных кобальта и никеля, вероятно, взаимодействуют путем комплексообразования с фторидионами поверхности кристалла, защищая поверхность от растворения.
Примеси кобальта и никеля не содержат кислород, находясь в кристалле. При выходе из дислокаций примеси кобальта и никеля окисляются на поверхности кристаллов $\mathrm{LiF}$ и $\mathrm{MgF}_{2}$ в атмосфере отжига.

Атомы металлов кобальта и никеля выходят на поверхность скола кристалла не только из ближайших к поверхности слоев, но и из последующих слоев кристалла во время термического травления в атмосфере и создают пленку оксидов переходных металлов.

Нагревание кристалла до соответствующей температуры приводит к тому, что на местах дислокаций протекает процесс преципитации декорирующих веществ, добавляемых намеренно, и имеющихся в решетке и в атмосфере отжига примесей. Затем примесь выходит из дислокаций, где она скопилась.

Показано, что при отжиге происходят „залечивание кристалла и выход примесей преимущественно из дислокаций и протяженных дефектов внутри кристалла. Проведением таких отжигов можно получать более совершенные кристаллы с изоморфным расположением намеренно вводимых примесей в узлах решетки. Кроме того, выход примесей из дислокаций и других объемных дефектов улучшает оптические свойства кристаллов, уменьшает количество светорассеивающих частиц, которые понижают КПД лазерных сред и ухудшают восстановление свойств дозиметров ионизирующих излучений на основе изученных нами кристаллических матриц после использования.

Дополнительного изучения требует вопрос о высокотемпературном движении примесно-вакансионных диполей и участии их в образовании наноразмерной металлической поверхностной пленки.

\section{Финансирование работы}

Работа выполнена при поддержке проекта II.10.1.2 программы II.10.1. фундаментальных исследований СО РАН на 2017-2020 гг. и НИОКТР № 1210331000066-3 Минобрнауки России „Прецизионные люминесцентные методы в лазерной физике и нанофотонике“.

Измерения выполнялись с использованием оборудования ЦКП „Байкальский центр нанотехнологий“.

\section{Конфликт интересов}

Авторы заявляют, что у них нет конфликта интересов.

\section{Список литературы}

[1] A. Dauletbekova, J. Maniks, I. Manika, R. Zabels, A.T. Akilbekov, M.V. Zdorovets, Y. Bikhert, K. Schwartz. Nucl. Instrum. Meth. Phys. Res. B 286, 56 (2012).

[2] S.A. Nebogin, N.A. Ivanov, L.I. Bryukvina, N.V. Shipitsin, A.E. Rzhechitskii, V.L. Paperny. PNFA 29, 36 (2018).

[3] V.I. Dubinko, D.I. Vainshtein, H.W. den Hartog. Nucl. Instrum. Meth.Phys. Res. B 228, 304 (2005). 
[4] Lyubov Bryukvina, Nikolay Ivanov, Sergey Nebogin. J. Phys. Chem. Solids 120, 133 (2018).

[5] Н.А. Иванов, Д.В. Иншаков, Е.А. Олейников, В.М. Хулугуров, А.И. Чернышов. ЖПС 54, 331 (1991).

[6] Л.И. Брюквина. ФТТ 61, 1852 (2019).

[7] А.А. Шалаев, Н.С. Бобина, А.С. Паклин, Р.Ю. Шендрик, А.И. Непомнящих. Изв. РАН. Сер. физ. 79, 287 (2015).

[8] С.А. Небогин, Л.И. Брюквина, Н.А. Иванов, М.Д. Зимин. Хим. физ. 37, 11 (2018).

[9] D.M. Rines, P.F. Moulton, D. Welford, G.A. Rines. Opt. Lett. 19, 628 1994).

[10] Lyubov Bryukvina. J. Lumin. 162, 145 (2015).

[11] Han Rao, Zhenhua Cong, Sasa Zhang, Yang Liu, Shaojie Men, Zhaojun Liu, Xingyu Zhang, Petr G. Zverev, Vasily A. Konyushkin, Houwen Yang, Wenyong Cheng, Yongfu Li. Opt. Express 23, 21884 (2015).

[12] Н.А. Иванов, Д.В. Иншаков, И.А. Парфианович, В.М. Хулугуров. ПЖТФ 12, 1250 (1986).

[13] L.I. Bryukvina, N.A. Ivanov. J. Fluorine Chem. 192A, 124 (2016).

[14] A. Lushchik, I. Kudryavtseva, P. Liblik, Ch. Lushchik, A.I. Nepomnyashchikh, K. Schwartz, E. Vasil'chenko. Rad. Meas. 43, 157 (2008).

[15] С.А. Небогин, Л.И. Брюквина, Н.А. Иванов, Д.С. Глазунов. ФTT 59, 1119 (2017).

[16] Sabar Bauk, Shah Alam, Ahmad Saleem Alzoubi. J. Phys. Sci. 22, 1, 125 (2011).

[17] L. Bryukvina. Open Acc. J. Chem. 4, 01 (2020).

[18] D.V. Martyshkin, J.G. Parker, V.V. Fedorov, S.B. Mirov. Appl. Phys. Lett. 84, 3022 (2004).

[19] V.M. Khulugurov, V.N. Salomatov, A. Vassilikou-Dova, V.I. Baryshnikov, I.M. Kalogeras, S. Grigorakakis, S.K. Makarov, A.A. Mikhalenko. J. Phys.: Condens. Matter 11, 7005 (1999).

[20] M. Ebrahim-Zadeh, I.T. Sorokina. Mid-Infrared Coherent Sources and Applications. NAPSB: Physics and Biophysics, Springer. Dordrecht (2008). P. 225-260.

[21] Yingying Zhang, Tingting Tan, Zhengtang Liu, Sha Liu, Jie Su. Vacuum 120A, 50 (2015).

[22] T. Ejima, W.H. Robinson, J.P. Hirth. J. Cryst. Growth 7, 155 (1970).

[23] A.R. Patel, S.K. Arora. J. Phys. D 7, 2301 (1974b).

[24] К. Сангвал. Травление кристаллов: теория, эксперимент, применение. Мир, М. (1990). 492 с.

[25] Н.А. Иванов, Д.В. Иншаков, Е.А. Олейников, Э.Э. Пензина, В.М. Хулугуров. Оптика и спектроскопия 71, 467 (1991).

[26] Л.И. Брюквина, Е.А. Ермолаева, С.Н. Пидгурский, Л.Ф. Суворова, В.М. Хулугуров. ФТТ 48, 64 (2006).

[27] S. Amelinckx. Acta Met. 2, 848 (1954).

[28] Mitsuru Yoshimatsu, Kazutake Kohra. J. Phys. Soc. Jpn 15, 1760 (1960).

[29] Mitsuru Yoshimatsu. J. Phys. Soc. Jpn. 16, 2246 (1961).

[30] C.C. Desai, K. Sangwal, V. John. Kristal. Tech. 12, 1269 (1977).

[31] M.B. Ives, J.P. Hirth. J. Chem. Phys. 33, 517 (1960).

[32] A. Grinberg. Phys. Status Solids 8, 1369 (1963).

[33] J. Budke. J. Appl. Phys. 40, 641 (1969).

[34] J.J. Gilman, W.G. Johnston, G.W. Sears. J. Appl. Phys. 29, 747 (1958).

Редактор К.В. Емщев 